\title{
Os ideais da formação humanista e o sentido da experiência escolar
}

José Sérgio Fonseca de Carvalho'

\section{Resumo}

A sensação de que a instituição escolar vive uma profunda crise é bastante generalizada, sobretudo entre intelectuais e profissionais da educação. 0 consenso acerca de sua existência, no entanto, não tem implicado qualquer concordância no que concerne aos elementos que a teriam precipitado ou às características de sua atual configuração. A hipótese que guia essas reflexões visa a associar a noção de uma crise na educação escolar a um aspecto que costuma permanecer oculto na maior parte dos discursos críticos acerca da escolarização contemporânea: o esvanecimento do sentido político e existencial da experiência escolar. A fim de desenvolver tal hipótese, debruçamo-nos, inicialmente, sobre a variedade de possíveis acepções do termo "crise", rejeitando aquelas que a vinculam de forma imediata às noções de declínio, decadência ou ocaso. A partir dos escritos de Arendt e Koselleck, a noção de crise é, então, utilizada em sua acepção primeira: a da emergência de um momento crucial que, por romper com respostas cristalizadas na tradição, exige reflexão e decisão. 0 que se procura realizar é, pois, um exercício de pensamento que recuse as abordagens funcionais e econômicas do sistema escolar em favor da compreensão de um sentido intrínseco para a experiência escolar: o da iniciação dos mais novos em heranças simbólicas capazes de dar inteligibilidade à experiência humana e durabilidade ao mundo comum. Uma iniciação cujo significado transcende qualquer funcionalidade exterior à experiência escolar, já que reside na própria formação de um sujeito, e não em sua possível inserção em um sistema produtivo.

\section{Palavras-chave}

Filosofia da educação - Arendt - Formação - Humanismo.

I- Universidade de São Paulo. São Paulo, SP,

Brasil.

Contato: jsfcusp@usp.br 


\title{
The ideals of a humanistic education (bildung) and the meaning of school experience
}

José Sérgio Fonseca de Carvalho'

\begin{abstract}
The feeling that the school institution is experiencing a deep crisis is quite widespread, especially among intellectuals and school professionals. The consensus about its existence, however, does not imply any agreement as far as its causes or current features are concerned. The hypothesis that guides the present reflections associates the notion of a crisis in education to one aspect that usually remains hidden in most critical discourses of contemporary education: the fading of a political and existential meaning for the school experience. In order to develop this hypothesis, the text focuses on the range of possible meanings of the term crisis, rejecting those that connect it immediately to notions of decay or decline of any sort. From the writings of Arendt and Koselleck, the notion of crisis is applied in its original Greek meaning: the emergence of a crucial moment that requires reflection and decision. Therefore, what I try to accomplish is an exercise of thought that refuses the functional and economic approaches of the school system, searching for an intrinsic meaning for school experience: the initiation of the new comers (children) in symbolic heritages capable of offering intelligibility to human experience and durability to our common world. An initiation whose meaning transcends any external functionality of the school experience in favor of a process whose final result is not a functional being, but an active subject.
\end{abstract}

\section{Keywords}

Philosophy of education - Arendt - Humanism - Liberal education.

I- Universidade de São Paulo. São Paulo, SP,

Brasil.

Contact: jsfcusp@usp.br 


\section{Os ideais da formação humanista e o sentido da experiência escolar}

Articular historicamente o passado não significa conhecê-lo "como ele de fato foi". Significa apropriar-se de uma reminiscência tal como ela relampeja no momento de um perigo. Walter Benjamin

A sensação de que a instituição escolar vive uma profunda crise é bastante generalizada, sobretudo entre intelectuais e profissionais da educação. 0 consenso acerca de sua existência, no entanto, não tem implicado qualquer concordância no que concerne aos elementos que a teriam precipitado ou mesmo às características de sua atual configuração. Para alguns, ela estaria vinculada à obsolescência de práticas pedagógicas herdadas de formas escolares tradicionais, enquanto, para outros, a crise atingiria a própria legitimidade dos conteúdos clássicos da educação escolar, cuja autoridade teria sido posta em questão a partir das transformações sociais e tecnológicas que marcaram o século XX. Há também aqueles que associam a existência de uma crise na educação ao declínio da distinção social que a escola foi um dia capaz de conferir aos poucos que logravam nela permanecer para além de seus anos iniciais. Outros, ainda, evocam seu poder de normalizar condutas ou de reproduzir desigualdades sociais a fim de desconstruir os discursos que atribuíam à escola um potencial emancipador que lhe conferia uma aura de prestígio social e político.

A hipótese que guia estas reflexões, mesmo sem a pretensão de polemizar diretamente com tais perspectivas críticas, procura associar a noção de uma crise na educação escolar a um aspecto que nelas sói permanecer oculto: o esvanecimento do sentido político e existencial da experiência escolar. Trata-se, contudo, de uma hipótese que requer alguns esclarecimentos prévios. Em primeiro lugar, porque concebe a escola não exclusivamente como um aparato estatal e burocrático ao qual se atribuem certas funções sociais e finalidades econômicas, mas também como um potencial lugar de experiências; como um palco para encontros intergeracionais mediados pelo diálogo com um conjunto de objetos e práticas culturais. Isso não implica - é evidente - negar a pertinência de uma perspectiva que busque compreender a escola como um dispositivo macrossocial a serviço, por exemplo, de uma ordem econômica ou da conformação a uma almejada confıguração social. Mas exige uma perspectiva analítica capaz de pôr em relevo a especificidade da forma escolar, de suas práticas, dos princípios que a animam e, sobretudo, dos significados compartilhados que seus agentes lhe atribuem em determinados contextos históricos. E um dos mais claros sintomas de crise nesse âmbito pode ser detectado pela dificuldade atual em se imputar à experiência escolar qualquer sentido existencial e político que ultrapasse suas alegadas funções econômicas ou seus supostos papéis na conformação e na reprodução de uma ordem social.

0 desenvolvimento dessa hipótese - que vincula a crise da educação escolar ao esvanecimento de seu sentido político e existencial - exige ainda um esforço preliminar com vistas a elucidar alguns de seus termos centrais: as noções de "crise" e de "sentido", conceitos complexos e polissêmicos cujo campo semântico permite uma série de acepções alternativas. Não é raro, por exemplo, que a noção de crise seja associada, de forma mais ou menos imediata, à ideia de declínio, decadência ou degeneração, muito provavelmente devido à generalização do uso que dela fazem os discursos econômicos.

De fato, nesse campo particular, o termo crise tem sido em geral empregado para descrever processos periódicos de desequilíbrio entre a produção e o consumo ou ainda para caracterizar o declínio e o subsequente desaparecimento de um determinado modo de produção. Mas a generalização dessa acepção bastante específica do termo crise não deve obliterar a amplitude de seu campo semântico, nem a variedade histórica e conceitual à qual ele está sujeito. Daí a relevância de se investigar, mesmo que de forma sumária, a gênese de seu uso e as formas pelas 
quais alguns pensadores o mobilizam em suas reflexões teóricas e redes conceituais.

Koselleck (2007), por exemplo, em sua obra Critica y crisis: un estúdio sobre la patogénesis del mundo burguês, ressalta que a

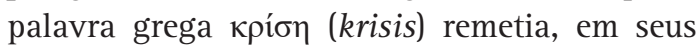
usos iniciais, às noções de cisão e de luta, estando vinculada à ação de um juiz (kritikós) cuja decisão estabelecia uma ruptura - ou um corte - no desenlace dos acontecimentos. Assim, no vocabulário legal, médico e militar, o reconhecimento da existência de uma crise indicava não necessariamente um declínio, mas a emergência de um evento crucial, de um momento capital que exigia julgamento e decisão, pois de seu desfecho poderia advir tanto a derrota quanto a vitória, tanto a vida quanto a morte. Trata-se, pois, de uma noção que comporta ruptura, mas também abertura; de um acontecimento cujo desenlace não é necessariamente a degeneração ou a decadência, já que traz consigo a oportunidade de exame do instituído e de sua eventual superação.

Essa ambivalência, consubstancial ao conceito de crise de acordo com Koselleck, marca de forma indelével a acepção que Arendt lhe confere em seus escritos sobre política e educação. Em A crise na educação, por exemplo, ela afırma que o aparecimento de uma crise "dilacera fachadas e oblitera preconceitos” (ARENDT, 2006, p. 171, tradução nossa), desafiando o pensamento e a ação a buscar respostas para o desaparecimento de padrões e critérios pelos quais até então nos guiávamos com algum grau de segurança. Isso porque uma crise, mais do que decadência ou degeneração, desvela a emergência do novo, do inesperado, daquilo que rompe com as certezas herdadas do passado. 0 que caracteriza uma crise é, pois, o fato de que, com seu aparecimento, acabamos por perder "as respostas em que nos apoiávamos de ordinário, sem sequer perceber que elas constituíam respostas a questões" (ARENDT, 2006, p. 171, tradução nossa).

Nesse sentido, afırmar a existência de uma crise ética, por exemplo, não implica alegar um suposto declínio nos padrões de conduta moral, mas tão simplesmente reconhecer que já não podemos contar com o legado de uma tradição ética para enfrentar os dilemas morais do presente. De forma análoga, identificar uma crise na educação não implica afirmar a existência de um declínio nos padrões de rendimento escolar ou qualquer sorte de decadência no que concerne às suas práticas ou ao seu papel social. Significa, antes, reconhecer que perdemos as respostas sobre as quais nos apoiávamos no que diz respeito aos procedimentos, às escolhas e, sobretudo, ao significado público que atribuímos ao processo educacional (0 que ensinar? Como? Em nome de que educar?). Significa ainda que não dispomos de critérios comuns e incontestes aos quais poderíamos recorrer na busca de tais respostas; que não compartilhamos regras ou princípios que possam nos guiar nessas decisões urgentes. Mas não implica que tenhamos perdido a capacidade de refletir e de propor sentidos para a prática educativa:

[...] uma crise só se torna um desastre quando a ela respondemos com julgamentos preconcebidos, isto é, com preconceitos. Uma atitude como essa não apenas aguça a crise como nos priva da experiência do real e da oportunidade que ele nos proporciona de refletir. (ARENDT, 2006, p. 171, tradução nossa).

Assim, uma crise na educação pode ser concebida como um momento crucial que enseja reflexão, julgamento e decisão, uma vez que os sentidos que historicamente lhe foram atribuídos já não parecem mais responder aos desafios do presente. Afirmar, contudo, o esvanecimento do sentido da experiência escolar pode parecer, à primeira vista, um paradoxo. Isso porque assistimos, já há algumas décadas, a uma profusão de discursos reiterando o papel central da educação escolar como instância privilegiada na formação do cidadão, no estabelecimento das bases para a expansão da empregabilidade das novas gerações ou na 
criação de uma cultura de sustentabilidade, para nos atermos apenas a algumas das mais recorrentes finalidades a ela atribuídas.

A enunciação de um conjunto de finalidades econômicas e sociais para a educação escolar não deve, entretanto, ser tomada como equivalente à atribuição de um sentido para sua existência. 0 caráter instrumental que marca o uso da noção de "finalidade" (expresso pela pergunta "para que serve...?”) vincula-se antes à lógica da fabricação e do uso de objetos do que à atribuição de um sentido para uma experiência política ou pessoal, cuja relevância não pode ser reduzida à sua capacidade de produzir os fins esperados a partir da escolha dos meios adequados. Vejamos alguns breves exemplos capazes de ilustrar a distinção conceitual entre as noções de finalidade e sentido.

Em geral, fabricamos uma mesa, por exemplo, não em função de qualquer sentido ou valor intrínseco - que possamos atribuir ao seu processo de produção ou ao objeto final dele decorrente, mas em função de uma finalidade prática que lhe é exterior. Noutras palavras, fabricamos ou compramos uma mesa por ela ser um meio conveniente ou necessário para um fim que lhe é exterior: ter um lugar para comer, apoiar um computador etc. Por outro lado, esse fim para o qual ela é um meio se transformará, também ele, em um novo meio para outro fim. Assim, fabricamos a mesa com a finalidade de apoiar um computador, que, por sua vez, transforma-se em um meio cujo fim é escrever um artigo ou obter informações, o que, por sua vez, torna-se um novo meio para outro fim. Cria-se, pois, uma cadeia infinita de meios que se transformam em novos fins que são, contudo, carentes de qualquer significado, já que destinados a se transformarem novamente em meros meios.

Ora, essa lógica instrumental - característica da produção e do uso de objetos - pode se tornar espúria quando aplicada ao âmbito da formação humana. Isso porque, nesse domínio particular - a exemplo de outros tantos campos da interação humana -, os critérios de julgamento e avaliação não são redutíveis às questões relativas, por exemplo, à eficácia ou eficiência dos meios empregados na consecução de um fim determinado. Nele, muitas vezes, não é possível sequer isolar a forma escolhida do próprio objetivo almejado. 0 êxito no ensino em um campo de conhecimento, como a ciência ou a filosofia, jamais se dissocia dos próprios valores que ele encarna, como a capacidade de testar uma hipótese ou de examinar criticamente seus argumentos, de sorte que uma formação científica ou filosófica dogmática encerra uma contradição em termos.

Acresce-se a isso o fato de que há um conjunto significativo de experiências humanas cujo valor ou importância não derivam de qualquer possível resultado que possam engendrar. Tais experiências têm, por assim dizer, um valor intrínseco, já que não necessariamente possuem uma utilidade imediata e, por vezes, sequer visam a atingir um fim exterior à própria experiência que engendram. As relações de amizade, a experiência da paternidade e o prazer de ler um poema são exemplos de experiências que podem ter um profundo sentido existencial e formativo para quem as vive, a despeito de sua vaga ou nula aplicabilidade prática imediata. $\mathrm{E}$ experiências dotadas de sentido são formativas não pelo que permitem fabricar como fruto de seu aprendizado, mas pelo fato de operarem transformações naqueles que por elas passam (CARVALHO, 2013). Por isso, uma experiência dotada de sentido formativo pode ser um elemento definidor na constituição de um sujeito, a despeito de sua pequena ou até nula utilidade prática.

Assim, o significado de uma experiência formativa - ou seu sentido existencial e político - não equivale a qualquer eventual finalidade instrumental. Ao contrário, sua compreensão desvela, antes, uma dignidade intrínseca à própria experiência, cuja razão de ser é a constituição de um sujeito e não a produção de um indivíduo em conformidade com demandas de cunho econômico ou social preestabelecidas. 


\section{Da dignidade da política à dignidade da experiência escolar}

Em um fragmento de uma obra inconclusa e publicada postumamente, a filósofa alemã Hannah Arendt tece suas reflexões sobre as vicissitudes da política no século XX a partir de uma pergunta que, à primeira vista, pode sugerir ceticismo e desesperança: "a política ainda tem algum sentido?” (ARENDT, 1993, p. 162). Não se trata, contudo, de uma interrogação de cunho niilista. Ao contrário, ela deve ser compreendida como mais uma de suas "perguntas antiniilistas feitas numa situação objetiva de niilismo em que o nada e o ninguém ameaçam destruir o mundo" (ARENDT, 2007, p. 269). A situação objetiva que a leva a propor a questão nesses termos é o preconceito do mundo moderno em relação à política; é a convicção nele generalizada de que é à política - e não à sua ausência - que se devem atribuir as trágicas experiências do totalitarismo, da ameaça nuclear e da desertificação de um mundo cuja durabilidade é posta em risco pela ascensão da produção e do consumo como objetivos supremos do viver juntos (CORREIA, 2003).

Nesse texto, como ao longo de grande parte de sua obra, Arendt procura recuperar o sentido e a dignidade da política, desvinculando-a do reducionismo a que foi submetida quando equiparada e limitada às atividades de governo e gestão estatal da sociedade. Não foi, pois, a expansão, mas o declínio do domínio político que tornou possível a emergência do totalitarismo, da tecnocracia e da burocracia como formas de dominação social. Isso porque, em Arendt, a política é uma forma peculiar e contingente de responder aos problemas da vida comum, ${ }^{1}$ que não se confunde com a dominação nem é

1- Em sua acepção cotidiana, o termo política aplica-se a toda e qualquer forma de governo ou dominação em uma sociedade. No quadro do pensamento de Arendt, no entanto, ele tem um significado bem preciso. Criada como uma forma de relação específica dos cidadãos entre si e com a polis - e reatualizada em outras criações históricas e sociais em alguma medida análogas -, a política pressupõe a primazia do discurso sobre a violência, a possibilidade da ação em concerto em um espaço comum, e se estrutura a partir do ideal da igualdade como princípio das relações na vida pública. Formas de gestão social fundadas na violência e no esvaziamento simples consequência do caráter gregário do animal humano. Ela é uma forma de vida (o que os gregos chamavam de um biós) cuja razão de ser é a liberdade e cuja condição de emergência é a criação de um espaço público comum e capaz de abrigar a pluralidade como marca do humano.

Assim concebida, a ação política não é uma necessidade humana, mas a frágil possibilidade de criação de um modo de vida "cujo impulso brota do desejo humano de estar na companhia dos outros, do amor ao mundo e da paixão pela liberdade" (CORREIA, 2010, p. XXXI). Um impulso que eclodiu em toda a sua grandeza na experiência democrática de Atenas, na estabilidade da Roma republicana, na breve existência dos conselhos populares que sucederam a revolução russa de 1917 ou dos que organizaram a revolução húngara de 1956 (DUARTE, 2000). Experiências que Arendt evoca não como modelos a serem reproduzidos, mas como acontecimentos cujo esplendor é capaz de iluminar aquilo que os eventos políticos do século XX obscureceram: que o sentido da política é a liberdade. Não a liberdade pessoal de deliberação e escolha em face de opções já dadas, mas a liberdade concebida como um atributo da vida política, ou seja, como a capacidade humana de romper com a reprodução dos automatismos do passado e imprimir ao fluxo dos acontecimentos um rumo até então inesperado. Nesse sentido, é a ação política que pode produzir o milagre do novo ${ }^{2}$ e, assim, salvar o mundo humano do desgaste e da ruína provocados pela passagem do tempo:

Entregues a si mesmos, os assuntos humanos só podem seguir a lei da mortalidade [...]. 0

do espaço público, como a tirania, a burocracia ou o totalitarismo, não são diferentes modalidades de política, mas sua negação.

2- Dada sua frequente conotação religiosa, a presença do termo milagre no texto de Arendt pode causar estranhamento. Não obstante, apesar de citar o Evangelho, Arendt se interessa não especificamente por seu sentido religioso e sobrenatural, mas por suas implicações filosóficas: "podemos negligenciar aqui as dificuldades [relativas às múltiplas acepções do termo] e nos referir apenas às passagens em que os milagres claramente não são eventos sobrenaturais, mas somente o que todos os milagres [...] devem ser sempre: interrupções de uma série natural de acontecimentos, de algum processo automático, em cujo contexto constituam o absolutamente inesperado" (ARENDT, 2006, p. 166, grifos nossos, tradução nossa). 
que interfere nessa lei é a faculdade de agir, uma vez que interrompe o curso inexorável e automático da vida cotidiana [...]. Prosseguindo na direção da morte, o período de vida do homem arrastaria inevitavelmente todas as coisas humanas para a ruína e a destruição, se não fosse a faculdade humana de interrompê-lo e iniciar algo novo, uma faculdade inerente à ação que é como um lembrete sempre-presente de que os homens, embora devam morrer, não nascem para morrer, mas para começar. (ARENDT, 2010, p. 307, grifos nossos).

Foi a radicalidade da questão formulada por Arendt - e os caminhos trilhados na proposição de sua resposta - que inspiraram a transposição dessa interrogação para o âmbito específico da experiência escolar: teria ela ainda algum sentido numa sociedade que trata o passado como obsoleto e o futuro como ameaçador? Tampouco nesse caso se deve tomar a forma interrogativa como indício de ceticismo. Tal como em Arendt, trata-se de uma pergunta antiniilista que se formula em oposição a um processo de crescente submissão da educação escolar a uma racionalidade instrumental que procura reduzir o ideal de uma formação educacional aos objetivos pragmáticos de uma conformação social ditada por imperativos econômicos. Um processo que, à força de tentar imprimir à escola toda sorte de finalidades extrínsecas, dela parece retirar qualquer sentido intrínseco. Um processo, pois, que reduz a experiência escolar a um meio cujo fim tem sido a mera adaptação funcional dos indivíduos aos reclamos de produção e consumo das sociedades contemporâneas, de forma a despojá-la de seu sentido intrínseco: a iniciação dos mais novos em heranças simbólicas capazes de dar inteligibilidade à experiência humana e durabilidade ao mundo comum (CARVALHO, 2013). Localizar nesses aspectos - a constituição de um sujeito e sua vinculação ao mundo comum a razão de ser da educação escolar não é uma arbitrariedade, ainda que inevitavelmente seja uma escolha programática (SCHEFFLER, 1968).
Programática porque sua enunciação implica um compromisso teórico fundado numa escolha valorativa - entre tantas outras possíveis -, com eventuais decorrências práticas e políticas. Mas não uma escolha arbitrária, visto que se ancora numa concepção de educação cujas raízes remontam a um acontecimento histórico inaugural: a fundação dos ideais educacionais que caracterizam o humanismo renascentista. A partir deles, a instituição escolar assume um novo papel social, pois não visa mais à preparação de um profissional especializado, mas à formação integral do homem e do cidadão. Trata-se, pois, de um acontecimento histórico que terá no âmbito da educação um papel análogo ao da democracia ateniense ou da república romana para a política: o de uma experiência fundadora da qual emanam princípios capazes de inspirar ações e orientar as inevitáveis transformações históricas a que uma instituição social está sempre sujeita. Assim, é no princípio da formação educacional humanista - entendido em sua dupla acepção de início e de preceito orientador ${ }^{3}$ - que se funda essa concepção de formação como a constituição de um sujeito em seu vínculo com o legado histórico de um mundo comum.

\section{A formação humanista como princípio inspirador da dignidade da experiência escolar}

Se, como propõe Arendt (2006, p. 153, tradução nossa), “é, de fato, difícil e até mesmo enganoso falar em política e em seus princípios sem recorrer, em alguma medida, às experiências da antiguidade grega $e$ romana”, o mesmo parece valer para o legado do humanismo renascentista no âmbito da educação. Ele se erigiu em referência histórica e conceitual dos discursos educacionais porque é fundamentalmente a partir de seus ideais e de suas práticas que a formação escolar adquire

3- Mesmo em seu uso ordinário, a língua portuguesa engloba e vincula essas duas acepções da palavra princípio. Houaiss (2008) a define como: "(1) o primeiro momento da existência (de algo), ou de uma ação ou processo [...]; (2) o que serve de base a alguma coisa; causa primeira, raiz, razão". 
um sentido público e histórico. É a partir do ideal educacional humanista que ela deixa de ser uma preparação profissional - ligada aos direitos, à medicina e, sobretudo, à teologia para ter como objetivo a formação do espírito, então entendida como a busca de cada um pela constituição de sua humanitas. Uma busca empreendida por meio do acesso direto ao legado cultural clássico; pelo estabelecimento de um processo formativo cujo resultado não é a aprendizagem instrumental de informações e conhecimentos especializados, mas a constituição de um sujeito que se insere na dimensão histórica de um mundo.

Nesse sentido, mais do que os conteúdos da cultura clássica - filosofia, história, dramaturgia e poesia -, é a própria noção grega de formação (Paidéia) que inspira os humanistas na elaboração de seu ideal educativo. Como destacam Masschelein e Simons, a escola grega clássica (a skholé, que em sentido estrito poderia ser traduzida por "tempo livre, adiamento, estudo, lugar de ensino" e cujo uso corrente pressupunha um distanciamento dos reclamos imediatos do mundo) surge como uma iniciativa política cujo objetivo era desvincular a ligação imediata entre nascimento e lugar social, tornando "inoperante a conexão arcaica que liga marcadores pessoais (raça, natureza, origem etc.) à lista de ocupações correspondentes aceitáveis" (MASSCHELEIN; SIMONS, 2013, p. 26). Esse tempo e esse espaço dedicados à formação - a skholé - instauram, pois

[...] um tempo livre, isto é, tempo não produtivo, para aqueles que por seu nascimento e seu lugar na sociedade (sua "posição") não tinham direito legítimo de reivindicá-lo. $\mathrm{Ou}$, dito ainda de outra forma, o que a escola fez foi estabelecer um tempo e espaço que estava, em certo sentido, separado do tempo e espaço tanto da sociedade (polis) quanto da família (oikós). Era também um tempo igualitário e, portanto, a invenção do escolar pode ser descrita como a democratização do tempo livre. (MASSCHELEIN; SIMONS, 2013, p. 26).
Assim, em sua gênese histórica, as noções de um tempo e de um espaço escolar implicavam, pois, a ideia de suspensão. Uma suspensão em relação às exigências imediatas da vida (trabalhar, cuidar da subsistência familiar, da ordem da cidade etc.) e em relação às desigualdades sociais fixadas pelo passado: ao tornar-se um estudante, a criança ou o jovem suspende temporariamente sua condição de filho, aristocrata, plebeu etc. para se caracterizar por sua atividade presente (afinal, o termo estudante designa apenas o particípio presente da ação de estudar!). É um tempo não produtivo no sentido preciso de que seu resultado não é a fabricação de um objeto ou instrumento (um bem de consumo ou de uso), mas a constituição de um sujeito.

É evidente que esse quadro traçado por Masschelein e Simons não se refere à totalidade e à complexidade da realidade histórica e educacional da Grécia clássica. Ele tão simplesmente procura iluminar o sentido de um acontecimento histórico que se materializou em iniciativas educacionais importantes e cujos primórdios e princípios remontam ao início do século $\mathrm{V}$ a.C., momento em que mesmo a prática de exercícios físicos se dissocia de sua aplicação militar imediata para ser concebida como uma arte ligada à perfeição formal e à formação moral (cf. MARROU, 1948). A visão instrumental da educação oferecida por alguns sofistas, voltada prioritariamente para a eficácia no campo da persuasão política, atesta que os ideais de formação eram então - e permanecem sendo - objeto de disputas entre visões não só distintas, mas muitas vezes antagônicas. Contudo, a vinculação da educação a um empreendimento de cunho ético voltado para o florescimento de uma vida interior - e não com uma aplicação prática imediata de informações e capacidades - irá se consolidar como referência a partir de Sócrates e, sobretudo, de Isócrates. E, tanto nos esforços pedagógicos dos chamados socráticos menores como em Isócrates, é na cultura literária helênica que os educadores encontram a chave para a compreensão da 
condição humana; daí sua dedicação ao estudo sistemático da filosofia, das criações poéticas e da dramaturgia. ${ }^{4}$

Ainda mais importante é o fato de que, com o advento das escolas gregas, a figura do preceptor pouco a pouco cede seu lugar à do professor que se dirige a um grupo de estudantes - portanto, a um público -, e não a um indivíduo isolado. Forma-se, assim, a noção de escola como uma comunidade - por vezes bastante semelhante a uma confraria religiosa na qual mestres e estudantes compartilham a tarefa do estudo e da formação, entendida como uma busca de autocompreensão do humano e de seu papel no cosmos. É essa tradição que será evocada - e não simplesmente restaurada, mas renovada - a partir do Renascimento Carolíngio, tomando sua forma mais radical e profunda com o advento das instituições escolares idealizadas pelo humanismo no século $\mathrm{XV}$. Ao incorporar as práticas pedagógicas institucionais desenvolvidas pela escola latina medieval, mas vinculando-as aos ideais clássicos de formação, a educação humanista funda uma nova modalidade de relação entre a formação escolar e o domínio público. Nessa nova configuração escolar, a relação com a cultura letrada ${ }^{5}$ e com as artes clássicas passa a ser concebida como elemento constitutivo da formação integral do homem, e não mais

4- Em Protágoras, há uma passagem na qual é possível vislumbrar o significativo papel educativo então atribuído à leitura e à análise da poesia. Em um desafio dirigido a Sócrates, o grande sofista de Abdera afirma: "Um dos pontos fundamentais da educação é o conhecimento a fundo da poesia, a saber, a capacidade de discernir nas obras dos poetas 0 que foi dito com acerto e o que não foi, bem como a de explicá-las e de saber fundamentar, quando interrogado, suas conclusões" (PLATÃo, 2002, p. 89). Em que pesem as profundas divergências entre os ideais formativos de Sócrates e Protágoras, é notável o fato de que ambos reconhecem o valor formativo da poesia.

5- A expressão cultura letrada é aqui empregada na acepção que the confere Havelock (1996, p. 59, grifos nossos), para quem "a cultura letrada não pode ser definida como coextensiva à existência histórica da escrita no Egito ou na Mesopotâmia [...] [porque], embora a cultura letrada dependa da técnica utilizada na inscrição, ela não se define apenas pela existência dessa técnica. É uma condição social que pode ser definida apenas em termos de leitura". Assim, a existência da cultura letrada pressupõe um público leitor e uma forma de vida na qual essa atividade ocupe um lugar central na circulação do saber. Nesse sentido, o humanismo a faz renascer, já que a leitura e a escrita permaneceram sendo, durante a maior parte da Idade Média, privilégios de um grupo social bastante restrito. como pré-requisito para sua inserção em um determinado estamento social.

Tal ruptura com a herança escolástica não decorre, pois, de inovações no campo das práticas pedagógicas. Estas pouco diferem dos procedimentos que caracterizavam a escola latina medieval, mas apresentam duas inovações que imprimem um novo sentido para a escola enquanto espaço de formação:

O humanismo impôs aos ginásios de seu tempo seu ideal de uma Antiguidade separada pela história. Para o homem da Idade Média, a Antiguidade jamais havia cessado [...]. Para o humanista, ao contrário, a Antiguidade foi uma era de perfeição seguida de um longo período de barbárie. Tratava-se menos de continuar a Antiguidade [como no caso dos medievais] do que de retomá-la pela restauração da língua e pela familiaridade com os autores [...]. 0 contato com os autores antigos não se vinculava a fins utilitários, nem mesmo no que concerne ao aprimoramento da língua, mas a algo verdadeiramente novo: à formação do espírito, já que ele permitia aos contemporâneos aproximarem-se dos grandes modelos antigos. Com a concepção humanista de Antiguidade, aparecia, tanto no ensino como na sociedade, a noção até então desconhecida de cultura geral, por muito tempo identificada como "humanidades". (ARIÈS, 2003, p. 9, grifos nossos, tradução nossa).

Diferentemente de sua antecessora, a escola renascentista não atribuía um valor apenas instrumental ao conhecimento; ela o estimava por seu potencial formativo. Não lhe interessava a preparação de especialistas, mas a formação de homens que, para além das diferenças ligadas à profıssão, origem social ou crença religiosa, partilhassem uma cultura comum e a responsabilidade pelos rumos históricos de sua res publica. É nesse sentido que o contato com a poesia, a filosofia, as 
artes e a história deveria ter um caráter liberal: seu papel era o de possibilitar, por meio do diálogo com esse legado clássico, que cada um viesse a cultivar seu espírito e a desenvolver sua personalidade liberado das contingências de sua ascendência familiar e de expectativas predeterminadas quanto ao seu papel social.

Assim, a noção de cultura geral atribui à educação um significado intrínseco: ela passa a ser um bem em si mesma, independentemente de possíveis - e imprevisíveis - efeitos exteriores à constituição do sujeito que se educa, como eventuais impactos na distribuição de riquezas ou de poder numa dada estrutura social. É nesse sentido que se deve compreender a afırmação de Lefort (1992, p. 211, tradução nossa) de que, com o humanismo, "a educação ganha valor em si, revela-se em busca de si mesma e engendra, na prática, um discurso que a visa como tal".

Essa nova concepção do papel do acesso à cultura clássica na formação geral de um cidadão veio acompanhada de uma nova percepção do presente em sua relação com o passado. Se o homem medieval assimilava a Antiguidade clássica ao seu presente - representando, por exemplo, Hércules como um cavaleiro ${ }^{6}$-, os humanistas a concebiam como um passado a um só tempo distante e inspirador. Distante porque entre eles e os antigos se interpunha a longa e obscura Idade Média, mas próximo porque, por meio da restauração da cultura antiga, os humanistas visavam a construir sua identidade como herdeiros da Antiguidade. Herdeiros porque capazes de reconstruir, a partir da crítica histórica e filológica, o verdadeiro significado de seu legado artístico e filosófico, mas também porque restauradores de uma ética da vita activa, segundo a qual a dignidade do

6- Segundo Garin (2003), um claro exemplo dessa assimilação em que 0 antigo se mescla com 0 medieval ocorre nas representações de figuras caras aos antigos, como a de Hércules. Ao longo dos séculos, este passa a ser representado ora como Cristo, ora como um cavaleiro medieval com suas vestes e armaduras, sem nenhuma preocupação em relação à sua imagem ou ao seu papel para os gregos antigos. Nessas representações, não há, pois, uma clara distinção entre o passado e o presente. Daí a convicção dos humanistas de que eles seriam os verdadeiros herdeiros da Antiguidade clássica, pois seus estudos visavam a restituir aos textos e à própria língua suas formas e seus sentidos originais, ou seja, clássicos. homem vincula-se ao seu engajamento na vida pública da civitas (cidade). Assim, a formação humanista se dava na forma de um diálogo:

Um diálogo com os mortos, porém com os mortos que, desde o momento em que falam, desde que são levados a falar, estão mais vivos que os seres próximos, vivendo uma vida totalmente diferente, são imortais no espaço da humanidade, comunicam sua imortalidade àqueles que se voltam para eles aqui e agora. (LEFORT, 1992 p. 212, tradução nossa).

É desse diálogo que emerge, entre os humanistas, o senso da história, da relação do presente com o passado e com o futuro como forma de constituição de um mundo comum que transcenda o espaço e se enraíze no tempo. Assim, os estudos das humanidades visavam a uma formação inicial comum e prévia à preparação profissional especializada; um tipo de formação escolar na qual o contato com o legado cultural de uma civilização tinha uma dimensão simultaneamente ética, estética e política.

Tratava-se, portanto, de uma forma específica de se aproximar do passado com vistas a compreender e definir o presente, propiciando uma oportunidade de vínculo com a profundidade histórica da existência humana, pois, como nos lembra Arendt (2006, p. 94, tradução nossa), "a profundidade não pode ser alcançada pelo homem a não ser por meio da recordação". Assim, é por meio da evocação de obras, atos e palavras memoráveis que se reificam objetos, textos e narrativas da cultura clássica, que o passado adquire, para os educadores humanistas, um caráter liberador em relação a toda sorte de tiranias que as demandas do presente possam vir a representar:

0 humanismo havia descoberto que o objetivo da educação era formar o homem, dar-lhe sua liberdade no mundo, torná-lo senhor do reino que Deus lhe havia concedido. Mas, precisamente a fim de não diminuir 
essa liberdade tão paradoxal, ele atribui à educação a missão de liberar o homem, de não o definir nem o coagir, de dar-lhe todo o poder em relação à consciência de si mesmo. Educar o homem é torná-lo consciente de si mesmo, de seu lugar no mundo e na história. 0 estudo dos antigos e de sua língua deveria justamente servir a esse fim: levar o homem, para além de qualquer definição, a se sentir senhor de si mesmo. (GARIN, 2003, p. 218, tradução nossa).

Ora, o que esse excerto de Garin nos sugere é, pois, que o sentido último da formação humanista é seu potencial caráter emancipador: a liberdade no mundo e a consciência de si mesmo. Não a consciência de um indivíduo apartado da pluralidade dos homens que habitam um mundo comum, mas antes a formação de um ser singular que se constitui por meio "de sua relação com a humanidade e com sua obra na história" (GARIN, 2003, p. 16, tradução nossa).

Assim, se é possível apontar um princípio fundamental da educação humanista, este reside menos nos conteúdos cristalizados por uma experiência histórica determinada do que no espírito que a moveu em direção a essa escolha. É na recusa à subserviência da cultura a qualquer sorte de instrumentalismo imediato que radicam o ideal de uma educação emancipadora e o sentido de uma formação escolar que com ela se comprometa. Nessa perspectiva, pouco importa se a cultura com a qual a instituição escolar dialoga é a da Antiguidade clássica, a do Iluminismo europeu, a dos povos americanos pré-colombianos ou aquela presente em suas manifestações mais recentes e pontuais. 0 que importa é a iniciação dos mais novos em um diálogo com um legado de realizações e experiências simbólicas que representem os esforços humanos não só a fim de prover sua subsistência, mas também de atribuir um sentido à sua existência social e política; um esforço histórico de constituição do humano a partir das diversas linguagens às quais os homens recorrem na busca de compreensão de sua condição de habitante de um mundo que se estende para além de sua existência individual, tanto no passado como no futuro. 0 ideal humanista de educação se apresenta, nesse sentido, como um tempo de formação no qual cada novo habitante do mundo é reconhecido como um sujeito de aprendizagem; e como um espaço de formação no qual, a partir do diálogo com uma pluralidade de vozes e linguagens que herdamos do passado, constituímo-nos como sujeitos do presente.

Concebida como uma oportunidade de diálogo com objetos da cultura e com o contexto histórico em que eles vieram a se constituir como um legado simbólico potencialmente comum, a formação escolar ganha um sentido que ultrapassa qualquer eventual finalidade pragmática que seus conteúdos possam conter. A essência do humanismo é, como nos recorda Arendt, a cultura animi: o cultivo desinteressado do espírito e do gosto; da capacidade de fruir, apreciar e julgar as instituições e obras que integram nosso mundo comum. Ele se vincula menos a um conteúdo cultural específico do que a uma forma de lidar com o mundo ou a um tipo de "atitude que sabe como preservar, admirar e cuidar das coisas do mundo" (ARENDT, 2006, p. 222, tradução nossa). Uma atitude que faz dos diversos legados culturais que coabitam nosso mundo contemporâneo uma potencial herança comum. Uma herança que nos chega sem testamento e que, portanto, exige de nós a coragem e a responsabilidade de fazer julgamentos e escolhas. Essas escolhas serão dignas da herança humanista na medida em que atualizarem seu compromisso ético e politico de propiciar aos que chegam ao mundo a oportunidade de "escolher suas companhias entre homens, entre coisas e entre pensamentos, tanto no presente como no passado" (ARENDT, 2006, p. 222, tradução nossa). 


\section{Referências}

ARENDT, Hannah. A condição humana. Rio de Janeiro: Forense, 2010.

ARENDT, Hannah. A dignidade da política. Rio de Janeiro: Relume Darumá, 1993.

ARENDT, Hannah. A promessa da política. São Paulo: Difel, 2007.

ARENDT, Hannah. Between the past and the future. New York: Penguin, 2006.

ARIĖS, Phillipe. Préface. In: GARIN, Eugenio. L'éducation de I'homme moderne. Paris: Fayard, 2003.

BENJAMIN, Walter. Magia e técnica, arte e política. São Paulo: Brasiliense, 1989.

CARVALHO, José Sérgio Fonseca de. Reflexões sobre educação, formação e esfera pública. Porto Alegre: Penso, 2013.

CORREIA, Adriano. Apresentação. In: ARENDT, Hannah. A condição humana. Rio de Janeiro: Forense, 2010.

CORREIA, Adriano. 0 desafio moderno. Hannah Arendt e a sociedade de consumo. In: MORAES, Eduardo Jardim de; BIGNOTTO, Newton (Org.). Hannah Arendt: diálogos, reflexões e memórias. Belo Horizonte: UFMG, 2003. p. 227-245.

DUARTE, André. 0 pensamento à sombra da ruptura: política e filosofia no pensamento de Hannah Arendt. São Paulo: Paz e Terra, 2000.

GARIN, Eugenio. L'éducation de l'homme moderne. Paris: Fayard, 2003.

HAVELOCK, Eric. A revolução da escrita na Grécia e suas conseqüências culturais. São Paulo: Edunesp, 1996.

HOUAISS, Antônio. Novo dicionário Houaiss da língua portuguesa. São Paulo: Objetiva, 2008

KOSELLECK, Reinhard. Crítica y crisis: un estudio sobre la patogénesis del mundo burgués. Madrid: Trotta, 2007.

LEFORT, Claude. Écrire à l'épreuve du politique. Paris: Calmann Lévy, 1992.

MARROU, Henri-Irénée. Histoire de l'éducation dans l'antiquité. Paris: Éditions du Seuil, 1948.

MASSCHELEIN, Jan; SIMONS, Maarten. Em defesa da escola: uma questão pública. Belo Horizonte: Autêntica, 2013.

PLATÃO. Protágoras. Tradução de Carlos Alberto Nunes. Belém: UFPA, 2002.

SCHEFFLER, Israel. A linguagem da educação. São Paulo: Edusp; Saraiva, 1968.

Recebido em: 15.04.2015

Aprovado em: 17.12.2015

José Sérgio Fonseca de Carvalho é livre-docente em filosofia da educação pela Faculdade de Educação da Universidade de São Paulo (USP). Foi pesquisador convidado da Universidade de Paris VII (2011-2012) e coordena o Grupo de Pesquisa em Direitos Humanos, Democracia, Política e Memória (GPDH) no Instituto de Estudos Avançados da USP. 